\title{
Compatibility Assessment of Commercial Cements with superplasticizers
}

\author{
$S$ Shrihari ${ }^{1}, M V$ Seshagiri $\mathrm{Rao}^{2}, V$ Srinivasa Reddy ${ }^{3}$, and $A m a n d u$ Manasa ${ }^{4}$ \\ ${ }^{1}$ Professor of Civil Engineering, VJIT, Hyderabad, India. Email: shriharistructure@gmail.com \\ ${ }^{2}$ Professor of Civil Engineering, CVR College of Engineering, Hyderabad, Telangana, India. Email: rao_vs_meduri@yahoo.com \\ ${ }^{3}$ Professor, Civil Engineering Department, GRIET, Hyderabad, Telangana, India. Email:vempada@gmail.com \\ ${ }^{4}$ Department of Civil Engineering, VJIT, Hyderabad, Telangana, India.
}

\begin{abstract}
In the present study, compatibility assessment of commercially available cements (OPC and PPC) and SNF \& PCE based super plasticizers are made by evaluating the workabilities, setting times and compressive strengths of M40 grade concrete mixes made with two different brands of cement and with two different chemical admixtures. The dosage of SNF and PCE based chemical admixtures to be used in M40 grade concrete is determined using marsh cone test. It was found that M40 concrete made with SNF based superplasticizer has achieved desired compressive strength than the concrete made with PCE based superplasticizer. This shows that SNF based superplasticizer is more compatible for M40 grade concrete than PCE based superplasticizer. So it is suggested that for the development of PPC based M40 grade concrete SNF superplasticizers can be used.
\end{abstract}

\section{Introduction}

Cement - superplasticizer interaction in concrete is a complex blend of chemical and physical mechanisms that are interdependent. The complicated nature of the problem prevents the development of simple solutions to address the field related issues of application of super plasticizers. Studies on cement-water reducer interactions in India have been limited to the workability evaluation of concretes containing these chemicals, in specific regions where rapid slump loss has been observed in concreting operations. There have not been any investigations to understand the physico-chemical nature of this interaction. Thus, the results from these studies are not broad-based, i.e. they apply to a small group of cements and/or chemical admixtures. There is a distinct need for the characterization of Indian cement and admixture properties, in order to understand the nature of their interactions.

\section{Objectives of the present work}

1. To determine the dosage of SNF and PCE based chemical admixtures to be used in M40 grade concrete.

2. To assess the workability of M40 grade concrete mixes made with two different brands of cement and with two different chemical admixtures
3. To determine setting times of M40 grade concrete mixes made with two different brands of cement for assessment of compatibility with two different chemical admixtures.

4. To evaluate compressive strengths of M40 grade concrete mixes made with two different brands of cement for assessment of compatibility with two different chemical admixtures.

\section{Materials Used}

The use of locally available materials from different sources was emphasized in this study. For the cases where locally available materials were not attainable, commercially available materials were used. Following are the details of materials used.

To select the brands of cement for the study, a survey is conducted to find the types of cements and different brands of cements in various sites in Hyderabad city. From the survey conducted in 25 sites in and around city it was found that brand 1-OPC cement is used in 35\% sites and brand 2PPC cement is used in $40 \%$ sites. For the present study, the PCE based and SNF based chemical admixtures are used. Hence this study aims to provide a database for the construction sites in Hyderabad city in deciding the 
optimum dosage for different brands/types of cement for the selected admixture type.

Cements used - (1) Brand 1 -OPC; (2) Brand -2 -PPC

The grade of concrete used in the present investigation are standard grade (M40). The mix proportions of M40 grade concrete is designed using IS: 10262-2009. The mix proportions and materials required for one cubic meter of concrete in standard grade (M40) is evaluated.

\section{Marsh Cone Method for Determining Optimum Dosage of Admixture}

Marsh cone test is dependable and simple method to study the rheological properties of cements and mortars. Flow time of cement through marsh cone is indicator of viscosity, which depends upon cement-admixture compatibility. It is widely used to study cement- admixture compatibility and to determine optimum admixture dosage of a specific cement-admixture combination. The main principle behind the test is to find the time required for a certain quantity of material (cement slurry) to flow out the cone through a particular size of aperture. The parameters flow time and fluidity are inversely proportional. As flow time increases fluidity decreases.

Graphs were plotted with \% admixture dosage on $\mathrm{X}$ axis and flow time on Y axis for the two brands of PPC cement at 0 minute, 30 minutes and 60 minutes retention. The dosage after which there is no change in flow time for 0 minute retention is noted as optimum dosage of admixture.

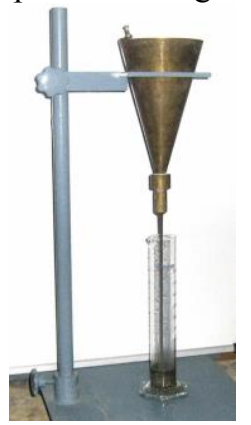

Fig.1. Marsh Cone Test

\section{Workability}

The slump is determined as. Per IS 1199: (1959) using standard slump cone apparatus.

\section{Setting times of concrete}

The setting times of concrete are determined as per IS 8142 (1976) using penetration resistance apparatus. Mortar passing through $4.75 \mathrm{~mm}$ sieve is separated from concrete this test. According to IS 8142 (1976), the initial setting time is the elapsed time, after initial contact of cement and water, required for the mortar (sieved from the concrete) to reach a penetration resistance of $3.43 \mathrm{~N} / \mathrm{mm}^{2}$ and final setting time is the elapsed time, after initial contact of cement and water, for the mortar (sieved from the concrete) to reach a penetration resistance of $26.97 \mathrm{~N} / \mathrm{mm}^{2}$

\section{Preparation of sample for setting times of concrete}

The concrete produced is sieved through a $4.75 \mathrm{~mm}$ sieve into a non-absorptive surface. The mortar which is passed through this sieve is remixed by hand and placed in the test container or three cube moulds of size $150 \mathrm{~mm}$ to a depth of $140 \mathrm{~mm}$ in layers of $50 \mathrm{~mm}$ duly compacted by rodding each layer by means of tamping rod with uniformly distributed strokes. The top surface of concrete is kept $13 \mathrm{~mm}$ below the top of mould to remove the free water from surface. The top surface of specimen is covered and protected with a suitable tight fitting, water impermeable cover for duration of the test, except when free surface water is being removed or penetration tests are being made. The free surface water is removed with the help of a pipette

\subsection{Apparatus for determining setting time of concrete}

A penetration resistance apparatus of spring reaction type, graduated from $0 \mathrm{kgf}$ to $60 \mathrm{kgf}$ in increments of $1 \mathrm{kgf}$ is used. Removable needles of $645,323,161,65,32$ and $16 \mathrm{~mm}^{2}$ bearing areas are used. Each needle shank is scribed peripherally at a distance of $25 \mathrm{~mm}$ above the bearing face. The photograph of apparatus is shown in Fig 4.

A needle of appropriate size depending upon the state of hardening of the mortar is fixed to the apparatus. The bearing surface of the needle is brought into contact with the mortar surface and a vertical force is applied gradually and uniformly on the apparatus until the needle penetrates the mortar to a depth of $25 \mathrm{~mm}$ as indicated by the scribe mark. The force required and the times of application are recorded. Sufficient care is taken in subsequent tests to avoid area where the mortar has been disturbed by previous tests. As per IS 8142 (1976), the clear distance between two needle impressions shall be at least two diameters of the needle being used, but not less than $13 \mathrm{~mm}$ and the clear distance between any needle impression and the side of the container shall be not less than $25 \mathrm{~mm}$. Photographs taken during the test are shown in Fig 5.

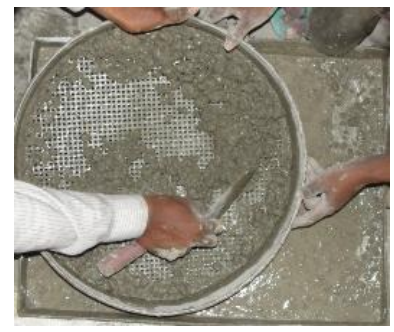

Fig. 2. Sieving of concrete through $4.75 \mathrm{~mm}$ sieve

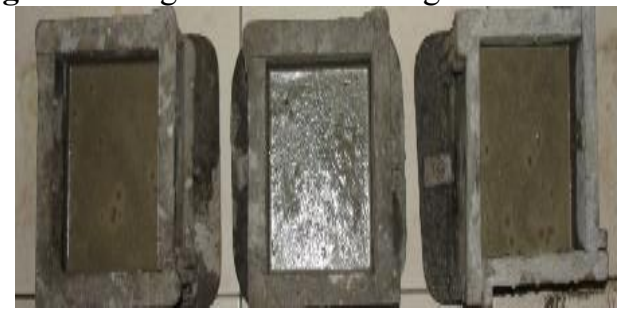


Fig. 3. Preparation of sample

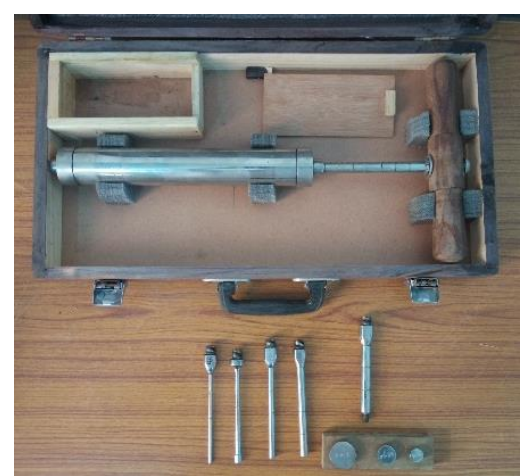

Fig. 4. Penetration resistance apparatus proctor penetrometer for setting times of concrete

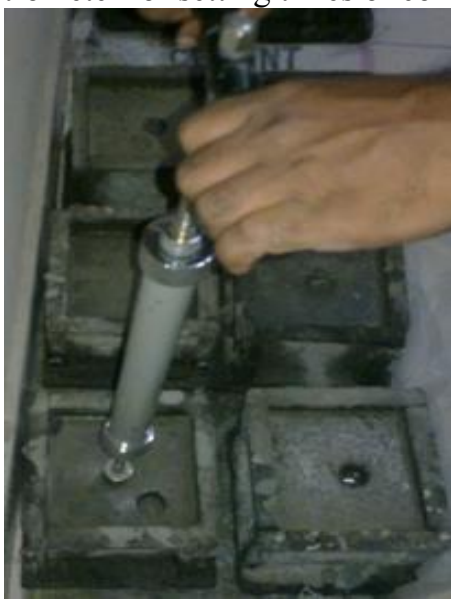

Fig. 5. Setting times of concrete by penetration resistance apparatus

An initial penetration test is done after an elapsed time of 4 to 6 hours, and subsequent test are carried out at intervals of half an hour to one hour depending upon the rate of hardening. The tests are carried out until a penetration resistance of at least $26.97 \mathrm{~N} / \mathrm{mm}^{2}$ is reached .The penetration resistance in $\mathrm{N} / \mathrm{mm}^{2}$ is calculated as the force required causing a $25 \mathrm{~mm}$ depth of penetration of the needle divided by the area of bearing surface of the needle.

The results are plotted showing penetration resistance in $\mathrm{N} / \mathrm{mm}^{2}$ as the ordinate and elapsed time in minutes as the abscissa. A smooth curve is drawn and the initial and final setting times as defined above are determined.

\section{Compressive strength}

Concrete cubes of M40 grade are tested to study the compressive strength under axial compression on completion of 28 days as per IS: 516-1999.

The test results of experimental investigations carried out are presented below in a systematic manner.

\section{Super plasticizer}

In the present work, water-reducing admixtures conforming to IS: $9103-1999$ used are
(1) Conplast SP 430 is a Sulphonated Naphthalene based Formaldehyde (SNF) super plasticizer manufactured by Fosroc.

(2) Glenium B233 manufactured by BASF which is a highperformance super plasticizer based on PCE (polycarboxylic ether).

\section{Mix Proportions}

The grade of concrete used in the present investigation is standard grade (M40). The mix proportions of M40 grade concrete are designed using IS: 10262-2009. The mix proportions and materials required for one cubic meter of concrete in standard grade (M40) is given in table below:

Table 1: Mix Proportions and quantities per $1 \mathrm{cu} . \mathrm{m}$. of M40 grade concrete

\begin{tabular}{|c|c|c|c|c|}
\hline Grade & $\begin{array}{c}\text { Cement } \\
\mathrm{kg} / \mathrm{m}^{3}\end{array}$ & $\begin{array}{c}\text { Fine } \\
\text { Aggregate } \\
\mathrm{kg} / \mathrm{m}^{3}\end{array}$ & $\begin{array}{c}\text { Coarse } \\
\text { Aggregate } \\
\mathrm{kg} / \mathrm{m}^{3}\end{array}$ & $\begin{array}{c}\text { Water } \\
\mathrm{L}\end{array}$ \\
\hline M40 & 390.7 & 876 & 999.7 & $164.1 \mathrm{~L}$ \\
\hline
\end{tabular}

*bwc-by weight of cement

\section{Test Results}

\subsection{March Cone Test Results}

Saturation dosage varies with the type of the superplasticizer and cement. Flow time decreases with increase in dosage of superplasticizer. The saturation dosage of admixture can be defined as that point beyond which there is no significant decrease in the flow time. Flow time after reaching saturation dosage is either same as saturation dosage or more or less constant after saturation point. Saturation point can be taken as the maximum admixture content to be used in concrete because there after no significant change will occur in flow time. SNF based superplasticizer optimum dosage for two brands of cement varies. Brand 1 showed $0.9 \%$ and brand 2 showed $1.1 \%$ saturation dosages at 0 minute retention. Flow time and \% dosage for brand 1 is lower than brand 2 . With the addition of admixture beyond $1.5 \%$, flow time has no variation. It may be due to the variation in chemical properties. From the results obtained it is observed that for both the selected cements their saturation dosage differs. Fineness of cement also plays a role in the variation of admixture dosage. As fineness increases surface area increases and resulting in more adsorption of admixture. Fineness is directly proportional to saturation dosage. As fineness increases saturation dosage also increases. Consistency, setting time etc. also depends on fineness. As fineness increases, setting time also increases. Flow time decreases as retention period increases and dosage at which flow time is lowest differ from 0 minute retention to 60 minute retention. Optimum dosage of brand 1 cement is $1.1 \%$ and that of brand 2 is $0.7 \%$ at 30 minute retention whereas optimum dosage of brand 1 cement is $0.9 \%$ and that of brand 2 is $0.7 \%$ at 60 minute retention. Similarly for PCE based the optimum 
dosage for Brand 1 showed $0.9 \%$ and brand 2 showed $0.7 \%$. Due to compatibility problems before application at fields compatibility check between cement and admixture should be done. So to reduce incompatibility problems check the compatibility whenever cement and admixture are changed.

\subsection{Workability}

The slump is determined as. Per IS 1199: (1959) using standard slump cone apparatus. It was understood from the literature that the increased rate of slump in the case of the concrete with admixture/superplasticizer is due to the effect of the gradual absorption of the water reducing agent by the product of hydration.

In SNF based concretes made with two brands of cement, desired workability is achieved in brand 2 than in brand 1 . Whereas in PCE based concretes made with two brands of cement, desired workability is not achieved in both the brands. So as far as workability required is concerned brand 2 performed better.

\subsection{Setting Times of Cement Concrete}

The trial mixes with mix proportions are prepared and the initial and final setting times of cement concrete are determined as per IS 8142:1976. The time interval for which the concrete remain in plastic condition is known as the setting time. The addition of superplasticizer to the concrete increases the setting times of the concrete.

Table 2. Workability

\begin{tabular}{|c|c|c|c|c|c|}
\hline \multirow{2}{*}{ Cement } & \multirow{2}{*}{ Grade } & \multirow{2}{*}{$\begin{array}{l}\text { Optimum Dosage of SNF based } \\
\text { superplasticizer (SP) }(\% \text { weight } \\
\text { of cement })\end{array}$} & \multicolumn{3}{|c|}{ Slump observed (mm) } \\
\hline & & & Initial & After $30 \mathrm{~min}$. & After $60 \mathrm{~min}$. \\
\hline Brand 1 & \multirow{2}{*}{ M40 } & 0.9 & 168 & 101 & 64 \\
\hline Brand 2 & & 0.7 & 150 & 92 & 53 \\
\hline \multirow[b]{2}{*}{ Cement } & \multirow[b]{2}{*}{ Grade } & \multirow{2}{*}{$\begin{array}{c}\text { Optimum Dosage of PCE based } \\
\text { superplasticizer (SP) } \% \text { weight } \\
\text { of cement })\end{array}$} & \multicolumn{2}{|c|}{ Slump observed (mm) } & \\
\hline & & & Initial & After $30 \mathrm{~min}$. & After $60 \mathrm{~min}$. \\
\hline Brand 1 & \multirow{2}{*}{ M40 } & 0.9 & 203 & 167 & 132 \\
\hline Brand 2 & & 0.7 & 250 & 192 & 153 \\
\hline
\end{tabular}

\begin{tabular}{|c|c|c|c|c|c|}
\hline \multirow[b]{2}{*}{ Cement } & \multirow[b]{2}{*}{ Grade } & \multirow{2}{*}{$\begin{array}{c}\text { Optimum Dosage of SNF based } \\
\text { superplasticizer (SP) }(\% \text { weight } \\
\text { of cement })\end{array}$} & \multicolumn{3}{|c|}{ Slump observed (mm) } \\
\hline & & & Initial & After $30 \mathrm{~min}$. & After $60 \mathrm{~min}$. \\
\hline Brand 1 & \multirow{2}{*}{ M40 } & 0.9 & 168 & 101 & 64 \\
\hline Brand 2 & & 0.7 & 150 & 92 & 53 \\
\hline \multirow[b]{2}{*}{ Cement } & \multirow[b]{2}{*}{ Grade } & \multirow{2}{*}{$\begin{array}{c}\text { Optimum Dosage of PCE based } \\
\text { superplasticizer (SP) }(\% \text { weight } \\
\text { of cement })\end{array}$} & \multicolumn{2}{|c|}{ Slump observed $(\mathrm{mm})$} & \\
\hline & & & Initial & After $30 \mathrm{~min}$. & After $60 \mathrm{~min}$. \\
\hline Brand 1 & \multirow{2}{*}{ M40 } & 0.9 & 203 & 167 & 132 \\
\hline Brand 2 & & 0.7 & 250 & 192 & 153 \\
\hline
\end{tabular}

Table 3: Penetration resistance of PCE based chemical admixtured M40 grade concrete made with brand 1 cement

\begin{tabular}{|c|c|c|c|c|c|}
\hline \multirow{2}{*}{$\begin{array}{c}\text { Time } \\
\text { elapsed } \\
\text { (hours) }\end{array}$} & \multirow{2}{*}{$\begin{array}{c}\text { C/s area of needle } \\
\text { used in } \mathrm{mm}^{2}\end{array}$} & \multicolumn{2}{|c|}{ Penetration resistance in (kgf) } & \multirow{2}{*}{ Force applied in N/mm ${ }^{2}$} \\
\cline { 5 - 6 } & 645 & 10 & 16 & 15 & 0.211 \\
\hline 7 & 645 & 29 & 30 & 27 & 0.237 \\
\hline 7.5 & 645 & 47 & 49 & 46 & 0.733 \\
\hline 8.5 & 323 & 32 & 32 & 29 & 0.959 \\
\hline 9.5 & 323 & 58 & 57 & 56 & 1.764 \\
\hline 10.5 & 161 & 32 & 39 & 38 & 2.25 \\
\hline 11.5 & 64 & 25 & 29 & 25 & 4.114 \\
\hline 12.5 & 64 & 56 & 55 & 56 & 8.541 \\
\hline 13.5 & 32 & 40 & 43 & 39 & 12.708 \\
\hline 14.5 & 32 & 59 & 58 & 58 & 3.225 \\
\hline 15.5 & 16 & 52 & 50 & 50 & 31.66 \\
\hline 16.5 & 16 & 60 & 60 & 60 & 37.5 \\
\hline 17.5 & & & & & \\
\hline
\end{tabular}

Four M40 grade concrete samples were prepared with 2 brands of cement and 2 types of admixtures and tested for setting times of concrete.

The setting time of concrete are determined as per IS: 8142(1976) using penetration resistance apparatus. Mortar passing through $4.75 \mathrm{~mm}$ sieve is separated from concrete for this test According to IS 8142 (1976), the initial setting me is the elapsed time, after initial contact of cement and water, required for the motor (sieved from the concrete) to reach a penetration resistance of $3.43 \mathrm{~N} / \mathrm{mm}^{2}$ and the final setting time is the elapsed time, after initial contact of cement and water, required for the mortar (sieved from the concrete) to reach a penetration resistance of $26.97 \mathrm{~N} / \mathrm{mm}^{2}$ We tested the initial and final setting times of concretes by the trial mixes with addition of superplasticizer. The penetration resistances of concrete mixes with superplasticizer are shown in Tables 3 to 6 .

M40 concrete made with SNF based superplasticizer has shown better initial and final setting times of concrete than in concrete made with PCE based superplasticizer. This shows that SNF based superplasticizer is more compatible for M40 grade concrete than PCE based superplasticizer. Same observations are made in concretes made with both brands of cement but Brand 2 showed better performance in setting times of concrete. 
Table 4: Penetration resistance of PCE based chemical admixtured M40 grade concrete made with brand 2 cement

\begin{tabular}{|c|c|c|c|c|c|}
\hline \multirow{2}{*}{$\begin{array}{c}\text { Time } \\
\text { elapsed } \\
\text { (hours) }\end{array}$} & \multirow{2}{*}{$\begin{array}{c}\text { C/s area of needle } \\
\text { used in } \mathrm{mm}^{2}\end{array}$} & \multicolumn{2}{|c|}{ Penetration Resistance in (kgf) } & \multirow{2}{*}{ Force applied in N/mm ${ }^{2}$} \\
\cline { 3 - 5 } & 645 & 18 & 20 & 22 & 0.31 \\
\hline 6.5 & 645 & 52 & 49 & 55 & 0.806 \\
\hline 7.5 & 323 & 40 & 38 & 42 & 1.238 \\
\hline 8.5 & 323 & 59 & 58 & 58 & 1.804 \\
\hline 9.5 & 161 & 43 & 49 & 52 & 2.981 \\
\hline 10.5 & 64 & 45 & 39 & 49 & 6.927 \\
\hline 11.5 & 32 & 29 & 30 & 36 & 9.895 \\
\hline 12.5 & 32 & 55 & 58 & 58 & 17.812 \\
\hline 13.5 & 16 & 45 & 48 & 49 & 29.58 \\
\hline 14.5 & 16 & 59 & 60 & 58 & 36.875 \\
\hline 15.5 & & & & \\
\hline
\end{tabular}

Table 5: Penetration resistance of SNF based chemical admixtured M40 grade concrete made with brand 1 cement

\begin{tabular}{|c|c|c|c|c|c|}
\hline \multirow{2}{*}{$\begin{array}{l}\text { Time elapsed } \\
\text { (hours) }\end{array}$} & \multirow{2}{*}{$\begin{array}{l}\mathrm{C} / \mathrm{s} \text { area of needle } \\
\text { used in } \mathrm{mm}^{2}\end{array}$} & \multicolumn{3}{|c|}{ Penetration resistance in (kgf) } & \multirow{2}{*}{ Force applied in $\mathrm{N} / \mathrm{mm}^{2}$} \\
\hline & & Specimen 1 & Specimen 2 & Specimen 3 & \\
\hline 4 & 645 & 7 & 8 & 7 & 0.113 \\
\hline 4.5 & 645 & 15 & 14 & 15 & 0.237 \\
\hline 5 & 645 & 45 & 44 & 45 & 0.69 \\
\hline 5.5 & 645 & 58 & 59 & 57 & 0.9 \\
\hline 6.5 & 323 & 47 & 48 & 47 & 1.47 \\
\hline 7.5 & 161 & 27 & 26 & 31 & 1.73 \\
\hline 8.5 & 161 & 45 & 48 & 42 & 2.81 \\
\hline 9.5 & 64 & 25 & 26 & 27 & 4.062 \\
\hline 10.5 & 64 & 45 & 47 & 47 & 7.23 \\
\hline 11.5 & 32 & 42 & 45 & 43 & 13.541 \\
\hline 12.5 & 16 & 29 & 34 & 30 & 19.375 \\
\hline 13.5 & 16 & 40 & 46 & 41 & 26.66 \\
\hline 14.5 & 16 & 60 & 59 & 60 & 37.29 \\
\hline
\end{tabular}

Table 6: Penetration resistance of SNF based chemical admixtured M40 grade concrete made with brand 2 cement

\begin{tabular}{|c|c|c|c|c|c|}
\hline \multirow{2}{*}{$\begin{array}{l}\text { Time elapsed } \\
\text { (hours) }\end{array}$} & \multirow{2}{*}{$\begin{array}{c}\mathrm{C} / \mathrm{s} \text { area of needle } \\
\text { used in } \mathrm{mm}^{2}\end{array}$} & \multicolumn{3}{|c|}{ Penetration resistance in (kgf) } & \multirow{2}{*}{$\begin{array}{l}\text { Force applied in } \\
\mathrm{N} / \mathrm{mm}^{2}\end{array}$} \\
\hline & & Specimen 1 & Specimen 2 & Specimen 3 & \\
\hline 6 & 645 & 9 & 9 & 10 & 0.144 \\
\hline 6.5 & 645 & 15 & 10 & 12 & 0.191 \\
\hline 7.5 & 645 & 43 & 47 & 46 & 0.702 \\
\hline 8.5 & 645 & 59 & 59 & 58 & 0.91 \\
\hline 9.5 & 323 & 55 & 57 & 58 & 1.754 \\
\hline 10.5 & 161 & 54 & 55 & 52 & 3.33 \\
\hline 11.5 & 64 & 44 & 50 & 39 & 6.92 \\
\hline 12.5 & 32 & 40 & 38 & 49 & 13.229 \\
\hline 13.5 & 16 & 41 & 38 & 43 & 25.41 \\
\hline 14.5 & 16 & 49 & 46 & 50 & 30.28 \\
\hline 15.5 & 16 & 59 & 58 & 60 & 36.875 \\
\hline
\end{tabular}




\subsection{Compressive Strength}

Compressive strengths of cement concrete at ages 28 days through normal curing is determined as per IS 516(1959). The experimental results and discussion of results are presented below.

Table 7. Compressive strengths of M40 grade concrete made with 2 brands of cement and 2 types of super plasticizers.

\begin{tabular}{|c|c|}
\hline Type of Concrete & $\begin{array}{c}\text { Compressive Strength } \\
(\mathrm{MPa}) \text { @ 28 days }\end{array}$ \\
\hline SNF based M40 -Brand1 & 49.34 \\
\hline SNF based M40- Brand 2 & 54.31 \\
\hline PCE based M40 -Brand1 & 41.23 \\
\hline PCE based M40- Brand 2 & 42.59 \\
\hline
\end{tabular}

M40 concrete made with SNF based superplasticizer has achieved desired compressive strength than the concrete made with PCE based superplasticizer. This shows that SNF based superplasticizer is more compatible for M40 grade concrete than PCE based superplasticizer. Same observations are made in concretes made with both brands of cement but brand 2 showed better performance in achieving strength of concrete.

So based on achievement of desired setting times and compressive strengths, it can be concluded that brand 2 cement based M40 concrete (ie, PPC based) is more compatible with SNF based superplasticizer than PCE based superplasticizer. So it is suggested that for the development of PPC based M40 grade concrete SNF superplasticizers can be used.

\section{Conclusions}

Based on experiments conducted on 2 types of M40 concrete made with brans 1 and brand 2 cements and admixed with SNF and PCE based superplasticizers, the following conclusions are drawn:

1. The optimum dosage of superplasticizer for SNF based is $0.9 \%$ and $0.7 \%$ for concretes made with brand 1 and brand 2 respectively

2. In SNF based concretes made with two brands of cement, desired workability is achieved in brand 2 than in brand 1. Whereas in PCE based concretes made with two brands of cement, desired workability is not achieved in both the brands. So as far as workability required is concerned brand 2 performed better.

3. M40 concrete made with SNF based superplasticizer has shown better initial and final setting times of concrete than the concrete made with PCE based superplasticizer. This shows that SNF based superplasticizer is more compatible for M40 grade concrete than PCE based superplasticizer. Same observations are made in concretes made with both brands of cement but brand 2 showed better performance in setting times of concrete.

4. M40 concrete made with SNF based superplasticizer has achieved desired compressive strength than the concrete made with PCE based superplasticizer. This shows that SNF based superplasticizer is more compatible for M40 grade concrete than PCE based superplasticizer. Same observations are made in concretes made with both brands of cement but brand 2 showed better performance in achieving strength of concrete.

5. So based on achievement of desired setting times and compressive strengths, it can be concluded that brand 2 cement based M40 concrete (ie, PPC based) is more compatible with SNF based superplasticizer than PCE based superplasticizer. So it is suggested that for the development of PPC based M40 grade concrete SNF superplasticizers can be used.

6. The mix proportion is approximately same in all the mixes even though the workability, compressive strengths and setting times of cement concretes depending on the ingredients of the cements.

\section{References}

1. Aiad, Influence of time addition of superplasticizers on the rheological properties of fresh cement pastes, Cem Concr Res 33 (2003) $1229-1234$.

2. C. P. E. Bedard, and N. P. Mailvaganam, The use of chemical admixtures in concrete: Part II: Admixture-admixture compatibility and practical problems, ASCE Journal of Performance of Constructed Facilities (2005) 263-266.

3. S. Chandra, Bjornstrom, Influence of Cement and Superplasticizer type and dosage on the fluidity of cement mortars, Cem Concr Res 32 (2002) 1613 1619.

4. M. Collepardi, Admixtures used to enhance placing characteristics of concrete, Cem Concr Compose 20 (1998) 103-112.

5. E. Hanna, M. Ostiguy, K. Khalifé, O. Stoica, B.-G. Kim, C. Bédard, M. Saric- Coric, M. Baalbaki, S. Jiang, P.C. Nkinamubanzi, P.C. A?tcin, and N. Petrov, The importance of superplasticizers in modern concrete technology, CANMET/ACI International conference on superplasticizers and other chemical admixtures in concrete, ACI SP (2000).

6. Papayianni, G. Tsohos, N. Oikonomon, P. Marira, Influence of superplasticizer type and mix design parameters on the performance of them in concrete mixtures, Cem Concr Compose 27 (2005) 217222.

7. M. Yousuf, A. Mollah, P. Palta, T. R. Hess, R. K. Vempati and D. L. Cocke, Chemical and physical effects of sodium lignosulfonate superplasticizer on the hydration of portland cement and solidification/stabilization consequences, Cem Concr Res 25 (1995) 671-682. 